\title{
Correction: WDHD1 is essential for the survival of PTEN-inactive triple-negative breast cancer
}

Ayse Ertay, Huiquan Liu, Dian Liu, Ping Peng, Charlotte Hill, Hua Xiong, David Hancock, Xianglin Yuan, Marcin R. Przewloka (D, Mark Coldwell, Michael Howell, Paul Skipp, Rob M. Ewing, Julian Downward (D) and Yihua Wang (10)

\section{Correction to: Cell Death and Disease} https://doi.org/10.1038/s41419-020-03210-5 published online 21 November 2020

The original version of this article unfortunately contained a mistake. In the original publication, Supplementary Tables 1 and 2 were not the final version. This was a mistake made by the authors during the submission. This error does not affect any of the findings reported in the paper. The final version of Supplementary Tables 1 and 2 are now provided. The authors apologize for any confusion that this error may have caused. The original article has been corrected.

Published online: 15 March 2021 